\title{
International Journal of Endocrinology and Metabolic Disorders
}

\section{Using Cancer Gene Profiling to Distinguish Benign from Malignant Follicular Thyroid Lesions}

\section{Claire E Peeples ${ }^{1}$, Robert Simon ${ }^{1}$, Sapna Nagar ${ }^{1 *}$, Hugh S Chung ${ }^{1}$, Samreen Ahmed $^{2}$, Bryan Thibodeau ${ }^{2}$, George Wilson ${ }^{2}$, Graham Long' and Peter Czako ${ }^{1}$}

${ }^{I}$ Department of Surgery, Beaumont Health System, Royal Oak, MI, USA

'Biobank, Beaumont Research Institute, Beaumont Health System, Royal Oak, MI, USA

*Corresponding author: Sapna Nagar, MD, Department of Surgery, Beaumont Health System, 3601 West Thirteen Mile Road Royal Oak, MI,USA, E-mail: sapna.nagar@beaumont.edu
Received date: 23 May 2015; Accepted date: 09 June 2015; Published date: 15 June 2015.

Citation: Peeples CE, Simon R, Nagar S, Chung HS, Ahmed S, et al. (2015) Using Cancer Gene Profiling to Distinguish Benign from Malignant Follicular Thyroid Lesions. Int J Endocrinol Metab Disord 1(2): doi http:// dx.doi.org/10.16966/2380-548X.105

Copyright: (C) 2015 Peeples CE, et al. This is an open-access article distributed under the terms of the Creative Commons Attribution License, which permits unrestricted use, distribution, and reproduction in any medium, provided the original author and source are credited.

\begin{abstract}
Objective: Fine needle aspiration (FNA) is a procedure used in the diagnosis of thyroid nodules. A definitive diagnosis is not possible when FNA shows follicular cells, and therefore a surgical intervention is necessary. Identifying genetic expression patterns in FNA samples of indeterminate thyroid nodules could assist in distinguishing benign from malignant follicular thyroid lesions.

Methods: Patients with follicular cells on FNA and a pathologic diagnosis of either follicular thyroid adenoma (FTA) or carcinoma (FTC) were included. Thyroid tissue was collected at the time of definitive surgery. Quantitative reverse transcription polymerase chain reaction (qRT-PCR) was used with an array profiler including 84 genes involved in transformation and tumorigenesis. $\mathrm{RT}^{2}$ Profiler PCR array data analysis software identified fold-change based upon $\Delta \Delta \mathrm{Ct}$ calculations. Gene expression was normalized to five housekeeping genes.

Results: Nineteen patients were included: 10 with FTA and 9 with FTC on post-operative pathology. In the FTC group, 11 genes had greater than 2-fold up or down-regulation relative to the adenoma group; and two genes reached statistical significance, caspase-8 and IL-8 ( $p \leq 0.05$ ). Utilizing the Sub-Network Enrichment Analysis (SNEA) algorithm, sub-networks of genes involving the transforming growth factor (TGF) family and peroxisome proliferator-activated receptor delta (PPARס) family were both highly regulated.

Conclusions: Our preliminary data identify two potential genes that may aid in differentiating FTC from FTA, and demonstrates a potential role for qRT-PCR of FNA samples. This may contribute to the workup of thyroid nodules to ultimately guide the treatment of indeterminate follicular lesions.

Keywords: Fine needle aspiration; Follicular thyroid adenoma; Follicular thyroid carcinoma; Cancer gene profiling; Thyroid nodules

Abbreviations: FNA: Fine Needle Aspiration; FTC: Follicular Thyroid Carcinoma; FV-PTC: Follicular Variant of Papillary Thyroid Carcinoma; FTA: Follicular Thyroid Adenoma; GEC: Gene Expression Classifier; RNA: Ribonucleic Acid; cDNA: Complimentary Deoxyribonucleic Acid; qRTPCR: Quantitative Reverse Transcription Polymerase Chain Reaction; Ct: Cycle Threshold; B2M: Beta-2 Microglobulin; HPRT1: Hypoxanthine Phosphoribosyl transferase 1; RPL13A: Ribosomal Protein L13A; GAPDH: Glyceraldehyde 3-Phosphate Dehydrogenase; ACTB: Actin, Beta is a protein coding gene; PCR: Polymerase Chain Reaction; SNEA: Sub-Network Enrichment Analysis; CASP8: Caspase 8; IL8: Interleukin 8; TGF: Transforming Growth Factor; PPARס: Peroxisome Proliferator-Activated Receptor Delta; TRAIL: Tumor Necrosis Factor-Related ApoptosisInducing Ligand; TNF- $\alpha$ : Tumor Necrosis Factor-Alpha; TNFR: Tumor Necrosis Factor Receptor; CD40: Cluster of Differentiation 40 is a protein found on the surface of antigen presenting cells required for their activation; NF- KB: Nuclear Factor Kappa-Light-Chain-Enhancer of Activated B Cells; TGF- $\beta$ : Transforming Growth Factor Beta
\end{abstract}

\section{Introduction}

Approximately $5-10 \%$ of the general population is diagnosed with a thyroid nodule in their lifetime. Most thyroid nodules are benign; however, ruling out malignancy is necessary as this affects patient treatment and outcomes [1]. Fine needle aspiration (FNA) remains an integral component in the evaluation of a thyroid nodule, and has reduced the rate of thyroid surgery for patients with benign nodules. Previous experience has demonstrated that up to $86 \%$ of resected nodules were benign [2]. The benefits of FNA-directed evaluation of a nodule include simplicity of the procedure, economic efficiency and overall reliability to distinguish between benign and malignant disease [2-4]. Based on FNA results, a clinician makes informed decisions regarding further management options, including observation, repeat FNA or surgical intervention. While FNA is simple and accurate, there are particular scenarios where differentiation of benign and malignant cytology becomes difficult.

Clear recommendations can be made for FNA results that are Bethesda categories II, V or VI. Category III and IV lesions comprise up to $30 \%$ of all FNA biopsies, and may or may not harbor malignancy [5]. General guidelines advocate for surgical resection for these lesions to determine capsular or vascular invasion, which is consistent with malignancy. Of the lesions resected, only 15 to $30 \%$ are malignant follicular thyroid carcinoma (FTC) or follicular variant of papillary thyroid carcinoma (FV-PTC) $[2,6]$. The majority of pathologic findings are either follicular thyroid adenoma (FTA) or hyperplastic proliferations of follicular cells in a multi-nodular goiter [2]. Because most of these indeterminate nodules are benign on post-operative pathology, a surgical procedure could be avoided if more precise pre-operative testing were available.

A novel FNA-based assay in the form of a gene expression classifier (GEC) was developed by Afirma (San Francisco, CA) [7]. This was validated with encouraging results in analytical consistency and clinical applicability as a rule out test due to high sensitivity $[5,8]$. Another FNAbased assay that has yet to be independently validated is miRInform by Asuragen (Austin, Tx). This has been studied and has a high specificity, where one can rule out malignancy in indeterminate thyroid lesions [9]. All these tests show promise to help classify indeterminate lesions, but

Copyright: (C) 2015 Peeples CE, et al. This is an open-access article distributed under the terms of the Creative Commons Attribution License, which permits unrestricted use, distribution, and reproduction in any medium, provided the original author and source are credited 
have yet to gain widespread clinical use and may benefit from additional genetic markers.

Examining follicular thyroid lesions and their FNA samples for differential expression of particular genes implicated in oncogenesis may lead to identification of more biomarkers that can discriminate malignant follicular lesions from benign lesions. This study aims to identify candidate genetic markers using a wide array of previously identified genes implicated in carcinogenesis that may potentially distinguish between FTA and FTC, thereby leading to their potential use in a biomarker panel that may be used in the pre-operative clinical setting of indeterminate thyroid nodules.

\section{Methods}

\section{Sample collection}

The study was approved by our institutional review board, and consent was obtained from all patients prior to testing. From October 2009 to June 2011, all patients with thyroid nodules demonstrating follicular cells on pre-operative FNA were included. Patients were recommended surgical intervention by a single surgeon in the form of a thyroid lobectomy, total thyroidectomy, or lobectomy followed by completion thyroidectomy, based on current guidelines and a discussion between the patient and surgeon. Immediately following surgical resection, an ex vivo FNA was obtained of the nodule and the tissue was immersed in ribonucleic acid (RNA) later at room temperature for 24 hours and then stored at $-80^{\circ} \mathrm{C}$. Histopathologic diagnosis of all surgical specimens was confirmed by an independent, board-certified pathologist. If there was variability between the pre-operative FNA and the ex vivo FNA they were not included in the study analysis. Post-operative surgical specimens were analyzed and designated as either follicular or Hürthle cell adenoma or follicular or Hürthle cell carcinoma.

\section{RNA extraction and reverse transcription}

Tumor tissues were prepared for RNA extraction by Polytron homogenization of $3 \mathrm{mg}$ of tissue. Cellular material from tumor tissue was subjected to RNA extraction using an RNeasy Micro Kit (Qiagen, Valencia, CA) and complimentary deoxyribonucleic acid (cDNA) was synthesized by reverse transcription using $50 \mathrm{ng}$ of RNA with the RT ${ }^{2}$ Preamp cDNA synthesis Kit (Qiagen, Valencia, CA) according to the manufacturer's protocol.

\section{Quantitative Real-time PCR (qRT-PCR)}

Samples were subjected to quantitative reverse transcription polymerase chain reaction (qRT-PCR) using the $\mathrm{RT}^{2}$ Profiler PCR Cancer Pathway Finder Array (SABiosciences, Valencia, CA). This array profiles the expression of 84 genes involved in transformation and tumorigenesis. Gene expression levels were quantified using the Realplex Mastercycler system (Eppendorf, Hauppauge, NY). The following thermo-cycling condition was used: $95^{\circ} \mathrm{C}$ for $10 \mathrm{~min}, 40$ amplification cycles of $95^{\circ} \mathrm{C}$ for 15 seconds $/ 60^{\circ} \mathrm{C}$ for $1 \mathrm{~min}$, followed by a melt curve. Data was analyzed using the $\Delta \Delta \mathrm{Ct}$ method $\left(\Delta \Delta \mathrm{C}_{\mathrm{T}}=2^{-[\mathrm{CC} \text { malignant sample-Ct malignant housekeeping gene) }-(\mathrm{Ct}}\right.$ adenoma sample-Ct adenoma housekeeping gene) fold-change calculations. Gene expression was normalized to the average expression of 5 housekeeping genes (B2M, HPRT1, RPL13A, GAPDH, ACTB). Polymerase chain reaction (PCR) array results were imported into Ariadne Pathway Studio for sub-network enrichment analysis (SNEA). SNEA utilizes all data points to discover highly regulated gene expression sub-networks.

\section{Statistical analysis}

Due to the rare incidence of FTC, there were only nine FTC samples that we encountered at our institution during the study time period. During that same time period, the first ten FTA samples were collected and used for analysis. All of the normalized values and statistical analyses to generate $\mathrm{p}$-values from $t$-tests were determined using Data Assist software v 3.01 (Life Technologies, Carlsbad, CA).

\section{Results}

\section{Demographic data}

A total of 19 patients were studied: 10 with FTA and 9 had FTC on postoperative pathology. Females constituted the majority of patients (74\%), and mean age of the entire cohort was $52.4 \pm 13$ years. History of previous cancer, family history of thyroid disease, and history of hypothyroidism or hyperthyroidism were similar between groups. Patients with a suspected diagnosis of carcinoma on FNA were more likely to undergo a total thyroidectomy or lobectomy with completion thyroidectomy $(\mathrm{p}<0.0001)$. Patient demographics are listed in Table 1.

\section{Gene expression}

Genetic expression was obtained using the $\mathrm{RT}^{2}$ Profiler PCR Cancer Pathway Finder Array of 84 specific genes shown on Table 2. Percentages of genes that demonstrated expression in each sample were sub-divided into four groups by cycle threshold values $(\mathrm{Ct})$ : high expression $(\mathrm{Ct}<25)$, intermediate expression (Ct 25-30), low expression (Ct 30-35), and no detectable expression. The $\mathrm{Ct}$ value is inversely proportional to the gene expression, in other words, if a gene is highly expressed it will take fewer cycles to reach the set threshold compared to a gene that has low expression. Among FTA samples, $17 \%$ had high expression, $42 \%$ had intermediate expression, 29\% had low expression, and 12\% had no detectable expression. The FTC samples demonstrated a similar distribution, where $24 \%$ demonstrated high expression, $40 \%$ had intermediate expression, $24 \%$ had low expression and $12 \%$ no expression (Figure 1).

There were 11 genes in the FTC group that had at least a 2 -fold differential expression (up- or downregulation) relative to the FTA samples (Table 3). Nine of these were downregulated; however, only caspase 8 (CASP8) and interleukin 8 (IL8) demonstrated significant downregulation of genetic expression in the FTC group $(\mathrm{p} \leq 0.02)$ (Figure 2).

Utilizing the results of all 84 genes and SNEA, sub-networks of genes where expression is controlled by members of the transforming growth factor (TGF) family and by peroxisome proliferator-activated receptor delta (PPAR $\delta$ ) were found to be highly regulated (Figure 3). CASP8 is downregulated by the TGF family, while IL 8 is downregulated by the $\operatorname{PPAR} \delta$ family.

\section{Discussion}

The results of this study demonstrate that it is possible to effectively analyze the limited tissue obtained from an FNA of a follicular lesion. The current study analyzes indeterminate follicular lesions, utilizing an FNA-based assay and qRT-PCR analysis, and identified two potential gene

\begin{tabular}{|c|c|c|c|}
\hline & FTA & FTC & Total \\
\hline $\mathbf{N}$ & $10(53 \%)$ & $9(47 \%)$ & 19 \\
\hline Age (Mean, years) & $51 \pm 12$ & $54 \pm 14$ & $52 \pm 13$ \\
\hline \multicolumn{4}{|l|}{ Gender } \\
\hline Male & $2(20 \%)$ & $3(33 \%)$ & $5(26 \%)$ \\
\hline Female & $8(80 \%)$ & $6(67 \%)$ & $14(74 \%)$ \\
\hline \multicolumn{4}{|l|}{ Surgical Procedure } \\
\hline Lobectomy Alone & $9(90 \%)$ & $2(22 \%)$ & 11 \\
\hline Total Thyroidectomy & $1(10 \%)$ & $7(78 \%)$ & 8 \\
\hline $\begin{array}{l}\text { Lobectomy followed by } \\
\text { Completion }\end{array}$ & 0 & $6(50 \%)$ & 15 \\
\hline
\end{tabular}

FTA, follicular thyroid adenoma; FTC, follicular thyroid carcinoma

Table 1: Patient Demographic Data comparing FNA samples of FTA and FTC lesions 
Open Access

\begin{tabular}{|c|c|c|}
\hline $\begin{array}{l}\text { Cell Cycle Control } \& \\
\text { DNA Damage Repair }\end{array}$ & $\begin{array}{l}\text { Signal Transduction } \\
\text { Molecules and } \\
\text { Transcription Factors }\end{array}$ & Angiogenesis \\
\hline ATM & AKT1 & $\begin{array}{c}\text { ANGPT1 } \\
\text { (angiopoietin-1) }\end{array}$ \\
\hline BRCA1 & ERBB2 & $\begin{array}{c}\text { ANGPT2 } \\
\text { (angiopoietin-1) }\end{array}$ \\
\hline CCNE1 (Cyclin E1) & ETS2 & $\begin{array}{c}\text { COL18A1 } \\
\text { (endostatin) }\end{array}$ \\
\hline CDC25A & FOS & FGFR2 \\
\hline CDK2 & JUN & IFNA1 (IFNa) \\
\hline CDK4 & MAP2K1 (MEK) & IFNB1 (IFN $\beta$ ) \\
\hline CDKN1A (p21Waf1) & MYC & IGF1 \\
\hline CDKN2A (p16Ink4) & NFKB1 (NFKB) & IL8 \\
\hline CHEK2 (chk2/Rad53) & NFKBIA (IKB $\alpha)$ & PDGFA \\
\hline E2F1 & PIK3R1 (PI3K p85a) & PDGFBTEK (tie-2) \\
\hline MDM2 & RAF1 & TGFB1 \\
\hline RB1 & \multirow{4}{*}{ SNCG } & TGFBR1 (ALK-5) \\
\hline S100A4 & & $\begin{array}{c}\text { THBS1 } \\
\text { (thrombospondin-1) }\end{array}$ \\
\hline \multirow{2}{*}{ TP53 (P53) } & & TNF \\
\hline & & VEGFA \\
\hline$\frac{\text { Apoptosis and Cell }}{\text { Senescence }}$ & Adhesion & $\frac{\text { Invasion and }}{\text { Metastasis }}$ \\
\hline APAF1 & ITGA1 (integrin $\alpha 1$ ) & MET \\
\hline BAD & ITGA2 (integrin $\alpha 2$ ) & $\begin{array}{c}\text { MMP1 } \\
\text { (collagenase-1) }\end{array}$ \\
\hline BAX & ITGA3 (integrin a3) & MMP2 (gelatinase A) \\
\hline BCL2 & ITGA4 (integrin a4) & MMP9 (gelatinase B) \\
\hline BCL2L1 (bcl-X) & ITGAV (integrin $\alpha \mathrm{V}$ ) & MTA1 \\
\hline CASP8 & ITGB1 (integrin $\beta 1$ ) & MTA2 \\
\hline CFLAR (CASPER) & ITGB3 (integrin $\beta 3$ ) & NME1 \\
\hline FAS & ITGB5 (integrin $\beta 5$ ) & NME4 \\
\hline GZMA & MCAM & PLAU \\
\hline HTATIP2 & MTSS1 & PLAUR \\
\hline TERY (telomerase) & PNN & S100A4 \\
\hline $\begin{array}{l}\text { TNFRSF1A (TNF-a } \\
\text { receptor) }\end{array}$ & SYK & SERPINB5 (maspin) \\
\hline TNFRSF10B (DR5) & EPDR1 & SERPINE1 (PAI1) \\
\hline \multirow[t]{3}{*}{ TNFRSF25 (DR3) } & & TIMP1 \\
\hline & & TIMP3 \\
\hline & & TWIST1 \\
\hline
\end{tabular}

Table 2: Genes and their functions included on RT2 Profiler PCR Cancer Pathway Finder Array

\section{Distribution of Gene Expression in Follicular Adenomas and Carcinomas}

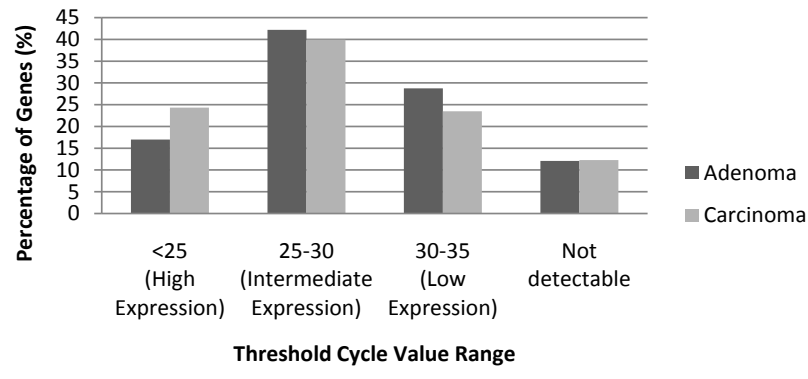

Figure 1: The percentage of genes that demonstrated expressions are shown and the $\mathrm{Ct}$ ranges for follicular adenomas are compared to $\mathrm{Ct}$ ranges for follicular carcinomas. The distribution is similar between FTA and FTC.

\begin{tabular}{|l|l|l|}
\multicolumn{1}{c|}{ Gene } & \multicolumn{1}{c|}{ Fold Change } & \multicolumn{2}{c|}{ P-value } \\
\hline ANGPT1 & -2.73 & 0.16 \\
\hline ANGPT2 & +2.46 & 0.23 \\
\hline CASP8 & -4.15 & $\mathbf{0 . 0 1}$ \\
\hline IFNA1 & -2.44 & 0.38 \\
\hline IGF1 & -2.23 & 0.13 \\
\hline IL8 & -3.37 & $\mathbf{0 . 0 2}$ \\
\hline ITGB3 & -2.14 & 0.57 \\
\hline PLAU & -3.58 & 0.06 \\
\hline TERT & -3.58 & 0.18 \\
\hline TIMP3 & -9.80 & 0.16 \\
\hline EPDR1 & +2.13 & 0.11 \\
\hline
\end{tabular}

Table 3: Reference genes with at least a 2 fold change and their respective P-values. Only Caspase 8 and IL-8 reached statistical significance.

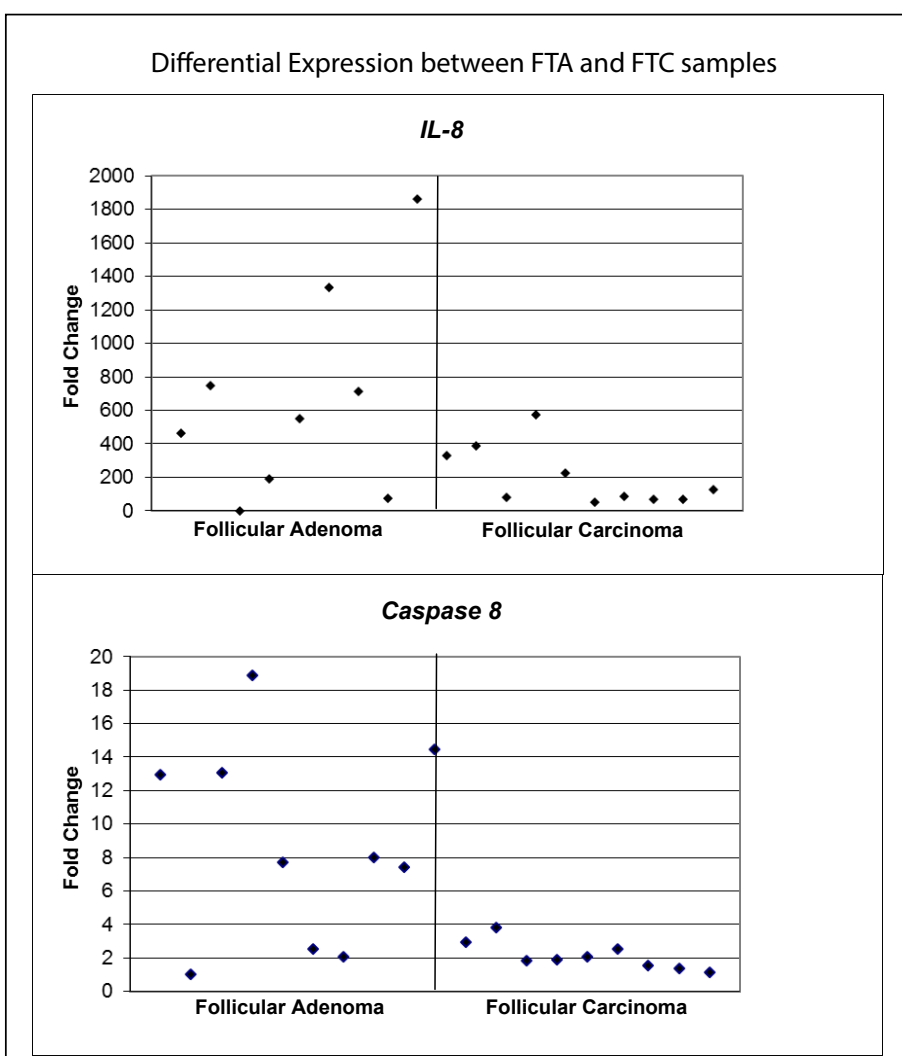

Figure 2: Fold change differential expression of IL-8 and caspase 8 in FTA vs. FTC samples. The expression values are presented as relative fold difference to the lowest expression level of IL-8 and caspase 8 , respectively, and normalized to the average of reference genes. IL-8 had an average 3.37 fold decrease for follicular carcinoma compared to follicular adenoma and caspase 8 had an average 4.15 fold decrease for follicular carcinoma compared to follicular adenoma.

candidates which may assist in distinguishing FTC from FTA: IL8 and CASP8. Overall, both genes demonstrated significantly decreased levels of expression in the FNA samples of follicular thyroid carcinoma compared to the FNA samples from follicular thyroid adenoma.

The importance of CASP 8 and IL8 in thyroid disease is possibly due to their involvement in angiogenesis, apoptosis, inflammation and cell senescence, which could explain their role in helping to distinguish malignant from benign lesions. In a mechanism initiated by tumor necrosis factor-related apoptosis-inducing ligand (TRAIL), procaspase- 8 is cleaved into its active form, caspase- 8 , which then promotes apoptosis [10]. It has been observed that this TRAIL-initiated cascade particularly 
targets cancer cells [11]. Lee et al. [12] demonstrated TRAIL-induced CASP8 mediated cytotoxicity in malignant fibrous histiocytoma. Similar to these findings, a reduction of caspase8 potentially abates the level of cell destruction and could lead to tumorigenesis, a finding consistent with the expression observed in the carcinoma samples.

Similarly, IL8 has been implicated in carcinogenesis due to the relationship with chronic inflammation and subsequent transformation to tumor cells in pancreatic and colon cancer $[13,14]$. However, it is not clear why $I L 8$ would have decreased expression in the carcinoma samples, considering its pro-inflammatory effect. A possible explanation for the reduced IL8 levels in this study is based on the established homology between tumor necrosis factor-alpha (TNF- $\alpha$ ) and TRAIL [15]. In cervical cancer cells, TNF- $\alpha$ and tumor necrosis factor receptor (TNFR)associated factor upregulate IL8 levels through CD40 and the NF- $\kappa B$ pathway, and TRAIL-induced expression of IL8 has been demonstrated in human intestinal epithelial cell lines $[16,17]$. If TRAIL expression was decreased, $I L 8$ may also be decreased as a result.

The interrelated pathways between TRAIL and TNF- $\alpha$ may support our basis of TRAIL as a central component in these observations. A decrease in TRAIL levels could provide reason for both the IL8 and CASP8 reductions. TRAIL is known to activate cell death in malignant cells while sparing normal cells and has also been shown to initiate apoptosis in premalignant cells [10]. While inhibiting the apoptosis mechanism promotes tumorigenesis, one may expect an inflammatory factor such as IL8 to have increased expression. However, a down-regulation of IL8 could be due to a disturbance in an upstream component. TRAIL deficiencies have been implicated in disruption of autoimmune and cell cycle regulation $[18,19]$. Therefore, it is possible that an inherent decrease in TRAIL expression ultimately leads to lowered CASP8 and IL8 levels, which is what we observed in our FTC samples. Ultimately, definitive conclusions regarding the TRAIL pathway requires direct measurements of the genetic marker within the follicular thyroid cancer specimens, and this may be an area for future research.

To help with interpretation of genetic expression levels and disease states, gene set enrichment methods have been introduced [20]. SNEA was developed to identify gene sets with significant concordant changes in expression between two conditions, i.e. adenoma versus carcinoma.

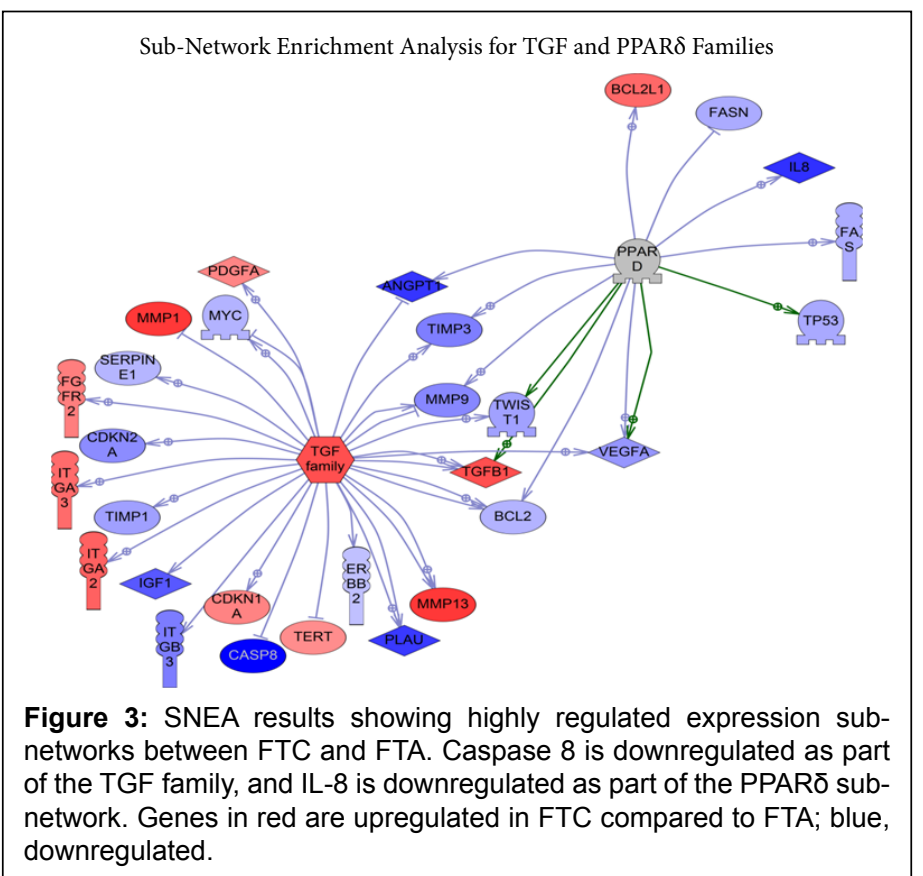

Each sub-network consists of a central entity that regulates the expression of downstream genes. Therefore, if the downstream expression targets contain more differentially expressed genes than expected by chance, the central entity is likely one of the activated regulators of the differential expression profile [20]. In our SNEA analysis, we were able to demonstrate two gene sub-networks that were highly regulated: expression targets of the TGF gene family and expression targets of PPAR $\delta$. PPARs are nuclear receptors that function as transcription factors, and PPAR $\delta$ exhibits anti-inflammatory and anti-carcinogenic effects through the $\beta$-catenin pathway. Transforming growth factor-beta (TGF- $\beta$ ) has been found to inhibit both the function and proliferation of epithelial cells; in tumor cells, these functions are reduced due to changes in the signaling pathways. This leads to uncontrolled proliferation and stimulation of invasion, metastasis and angiogenesis. The role of TGF- $\beta$ has been studied in thyroid carcinoma; however, studies remain inconclusive [21]. While TGF and PPAR $\delta$ may not have been shown thus far to have a direct relationship to the development of follicular carcinoma, perhaps a mechanism in these gene families is associated due to the upregulation of both IL8 and CASP8. These results point to a potential field for future investigation.

The limitation of this study is the small sample size. There were several other biomarkers approaching differences of statistical significance. Should a greater power be achieved, the interrelated pathways of the biomarkers could further support our results.

Our preliminary data demonstrate the potential for genetic discrimination between FTC and FTA using qRT-PCR in FNA samples. We highlight two possible candidate markers in CASP8 and IL8. In addition, gene expression sub-networks centered on TGF and PPAR $\delta$ are highly regulated in FTC, which shows promise for future research. This assay may prove valuable as a diagnostic tool to aid in the diagnosis and treatment of patients with indeterminate follicular lesions in the preoperative setting.

\section{References}

1. Cooper DS, Doherty GM, Haugen BR, Kloos RT, Lee SL, et al. (2009) Revised American Thyroid Association management guidelines for patients with thyroid nodules and differentiated thyroid cancer. Thyroid 19: $1167-1214$

2. Cibas ES, Ali SZ (2009) The Bethesda System For Reporting Thyroid Cytopathology. Am J Clin Pathol 132: 658-665.

3. Wu HH, Jones JN, Osman J (2006) Fine Needle Aspiration Cytology of the Thyroid: Ten Years Experience in a Community Teaching Hospital. Diagn Cytopathol 34: 93-96.

4. Redman R, Zalaznick H, Mazzaferri EL, Massoll NA (2006) The impact of assessing specimen adequacy and number of needle passes for fine-needle aspiration biopsy of thyroid nodules. Thyroid 16: 55-60.

5. Walsh PS, Wilde JI, Tom EY, Reynolds JD, Chen DC, et al. (2012) Analytical performance verification of a molecular diagnostic for cytology-indeterminate thyroid nodules. J Clin Endocrinol Metab 97: E2297-E2306.

6. Sherman SI (2003) Thyroid carcinoma. Lancet 361: 501-511.

7. Chudova D, Wilde JI, Wang ET, Wang H, Rabbee N, et al. (2010) Molecular classification of thyroid nodules using high-dimensionality genomic data. J Clin Endocrinol Metab 95: 5296-5304.

8. Alexander EK, Kennedy GC, Baloch ZW, Cibas ES, Chudova D, et al. (2012) Preoperative diagnosis of benign thyroid nodules with indeterminate cytology. N Engl J Med 367: 705-15.

9. Hodak SP, Rosenthal DS (2013) Information for Clinicians: Commercially Available Molecular Diagnosis Testing in the Evaluation of Thyroid Nodule Fine-Needle Aspiration Specimens. Thyroid 23: 131134

Citation: Peeples CE, Simon R, Nagar S, Chung HS, Ahmed S, et al. (2015) Using Cancer Gene Profiling to Distinguish Benign from Malignant Follicular Thyroid Lesions. Int J Endocrinol Metab Disord 1(2): doi http://dx.doi.org/10.16966/2380-548X.105 
10. Lu X, Arbiser JL, West J, Hoedt-Miller M, Sheridan A, et al. (2004) Tumor necrosis factor-related apoptosis-inducing ligand can induce apoptosis in subsets of premalignant cells. Am J Pathol 165: 16131620.

11. Rowinsky EK (2005) Targeted induction of apoptosis in cancer management: the emerging role of tumor necrosis factor-related apoptosis-inducing ligand receptor activating agents. J Clin Oncol 23: 9394-9407.

12. Lee HJ, Yang HM, Choi YS, Park SH, Moon SH, et al. (2013) A therapeutic strategy for metastatic malignant fibrous histiocytoma through mesenchymal stromal cell-mediated TRAIL production. Ann Surg 257: 952-960.

13. Asfaha S, Dubeykovskiy AN, Tomita H, Yang X, Stokes S, et al. (2013) Mice that express human interleukin-8 have increased mobilization of immature myeloid cells, which exacerbates inflammation and accelerates colon carcinogenesis. Gastroenterology 144: 155-166.

14. Farrow B, Sugiyama Y, Chen A, Uffort E, Nealon W, et al. (2004) Inflammatory mechanisms contributing to pancreatic cancer development. Ann Surg 239: 763-769.

15. Wiley SR, Schooley K, Smolak PJ, Din WS, Huang CP, et al. (1995) Identification and characterization of a new member of the TNF family that induces apoptosis. Immunity 3: 673-682.
16. Altenburg A, Baldus SE, Smola H, Pfister H, Hess S (1999) CD40 ligand-CD40 interaction induces chemokines in cervical carcinoma cells in synergism with IFN-gamma. J Immunol 162: 4140-4147.

17. Begue B, Wajant H, Bambou JC, Dubuquoy L, Siegmund D, et al. (2006) Implication of TNF-related apoptosis-inducing ligand in inflammatory intestinal epithelial lesions. Gastroenterology 130: 1962-1974.

18. Audo R, Calmon-Hamaty F, Baeten D, Bruyer A, Combe B, et al. (2011) Mechanisms and clinical relevance of TRAIL-triggered responses in the synovial fibroblasts of patients with rheumatoid arthritis. Arthritis Rheum 63: 904-913.

19. Lamhamedi-Cherradi SE, Zheng SJ, Maguschak KA, Peschon J, Chen $\mathrm{YH}$ (2003) Defective thymocyte apoptosis and accelerated autoimmune diseases in TRAIL-/- mice. Nat Immunol 4: 255-260.

20. Pyatnitskiy M, Mazo I, Shkrob M, Schwartz E, Kotelnikova E (2014) Clustering Gene Expression Regulators: New Approach to Disease Subtyping. PLoS One 9: e84955.

21. Pisarev M, Thomasz L, Juvenal GJ (2009) Role of Transforming Growth Factor Beta in the Regulation of Thyroid Function and Growth. Thyroid 19: 881-892. 